\title{
Predicting lake water quality responses to load reduction: a three-dimensional modeling approach for total maximum daily load
}

\author{
Z. Wang $\cdot$ R. Zou $\cdot$ X. Zhu $\cdot$ B. He $\cdot$ \\ G. Yuan $\cdot$ L. Zhao $\cdot$ Y. Liu
}

Received: 16 January 2012/Revised: 21 March 2012/ Accepted: 13 February 2013/Published online: 26 March 2013

(C) Islamic Azad University (IAU) 2013

\begin{abstract}
Water quality restoration efforts often suffer the risk of ineffectiveness and failure due to lack of quantitative decision supports. During the past two decades, the restoration of one of China's most heavily polluted lakes, Lake Dianchi, has experienced costly decision ineffectiveness with no detectable water quality improvement. The governments are planning to invest tremendous amount of funds in the next 5 years to continue the lake restoration process; however, without a quantitative understanding between the load reduction and the response in lake water quality, it is highly possible that these planned efforts would suffer the similar ineffectiveness as before. To provide scientifically sound decision support for guiding future load reduction efforts in Lake Dianchi Watershed, a sophisticated quantitative cause-and-effect
\end{abstract}

Electronic supplementary material The online version of this article (doi:10.1007/s13762-013-0210-7) contains supplementary material, which is available to authorized users.

Z. Wang

School of Resource and Environmental Science,

Wuhan University, 430079 Wuhan, China

R. Zou

Tetra Tech, Inc, 10306 Eaton Place, Ste 340, Fairfax, VA 22030, USA

X. Zhu · B. He - G. Yuan · L. Zhao

Yunnan Key Laboratory of Pollution Process and Management of Plateau Lake-Watershed, 650034 Kunming, China

Y. Liu $(\bowtie)$

College of Environmental Science and Engineering,

Peking University, The Key Laboratory of Water and

Sediment Sciences, Ministry of Education,

100871 Beijing, China

e-mail: yongliu@pku.edu.cn response system was developed using a three-dimensional modeling approach. It incorporates the complex three dimensional hydrodynamics, fate and transport of nutrients, as well as nutrient-algae interactions into one holistic framework. The model results show that the model performs well in reproducing the observed spatial pattern and temporal trends in water quality. The model was then applied to three total maximum daily load scenarios and two refined restoration scheme scenarios to quantify phytoplankton responses to various external load reduction intensities. The results show that the algal bloom in Lake Dianchi responds to load reduction in a complex and nonlinear way, therefore, it is necessary to apply the developed system for future load reduction and lake restoration schemes for more informed decision making and effective management.

Keywords Algae bloom - Water quality modeling . Scenario analysis - Total maximum daily load - Lake Dianchi

\section{Introduction}

Eutrophication resulting from society-mediated delivery of excess nutrients to receiving water-bodies is a threat to surface aquatic ecological systems across the world (Smith et al. 1999; Conley et al. 2009). The over-enrichment of nutrients can lead to serious eutrophication problems such as algal blooms, habitat loss, biodiversity changes, bottom oxygen depletion, and fishery loss (Diaz and Rosenberg 2008). The eutrophication control and water quality restoration for impaired waters pose a challenging problem for environmental decision makers due to the complex nonlinear cause-and-effect relationship between nutrient 
sources and water quality responses. Without a quantitative understanding about the response of eutrophication condition to different load control schemes, it would be very difficult for environmental managers to make informed and effective management decisions. In the past few decades, water quality modeling (WQM) has evolved into a scientifically sound technology to establish cause-and-effect relationship between load reduction and water quality responses, and has been widely used to support water quality management decision-making (Vieira and Lijklema 1989; Chapra 1997; Ahmad et al. 2001; Liu et al. 2008a; Zheng and Keller 2008; Zou et al. 2009; Zhao et al. 2011). WQM plays a central role in determining the Total Maximum Daily Loads (TMDL) requirements to achieve water quality standards and evaluating the effectiveness of pollutant control actions (National Research Council 2001; Lung 2001; Pelley 2003; Zou et al. 2006; Liu et al. 2008b). In addition, Sagehashi et al. (2000) applied a predictive model to simulate the long-term stability of shallow lakes after bio-manipulations. Gurkan et al. (2006) developed a structurally dynamic model for evaluating the effects of restoration on Lake Fure, Denmark. Martins et al. (2008) integrated mathematical modeling technology into decision processes to analyze prospective scenarios for reducing the risk of environmental degradation in Lake Sete Cidades (Portugal).

The development of sophisticated water quality model to support water quality management is of particular importance in China, where eutrophication control is among the top priority need and tremendous efforts have been and will be made to restore lake water qualities in the coming years (Ministry of Environmental Protection of China (MEP) 2008). For example, Lake Dianchi, China's sixth largest freshwater lake, has been suffering severe blue-green algae (BGA) bloom in the past decades (Yang et al. 2009), and is currently recognized as one of the most heavily polluted lakes in China (World Bank 2001; Liu et al. 2006).

Restoration of Lake Dianchi has been a top priority for local government in the past 20 years, and over two billion U.S Dollars have been invested to control watershed pollutant loading. However, due to lack of a scientificallysound quantitative understanding of the lake water quality response to management activities, the previous management efforts were based on un-informed decision making, causing unwise spending of restoration funds. As a consequence, after over 20 years of intensive restoration efforts, the water quality in Lake Dianchi demonstrates no sign of significant improvement. The government, scientists, and publics are puzzled and questions were raised on why the water quality never respond to all the implemented restoration efforts as expected, and how should future restoration efforts be designed to achieve better performance. This is particularly critical since the China central and local governments are planning to spend more in the next 5 years to restore the water quality in Lake Dianchi. The purposes of this study is to develop a decision support framework that would potentially answer the questions raised by the decision makers and publics, and guide a more effective and wise spending of the lake restoration funds for better results. The decision support system is based on a sophisticated three-dimensional hydrodynamic and water quality model. The model was calibrated and validated against observed historical data to assure that it reproduces the observed water quality pattern well. The calibrated and validated model was then used as the decision support system to analyze various load reduction scenarios to explore the complex cause-and-effect relationship between watershed loadings and in-lake eutrophication condition.

\section{Materials and methods}

\section{Study area}

Lake Dianchi, the largest lake in China's Southwestern Yunnan Province, is located south of the provincial capital city of Kunming at an altitude of 1,887.4 $\mathrm{m}$ above sea level (Fig. 1). It has a surface area of approximately $306.3 \mathrm{~km}^{2}$ and a watershed area of $2,920 \mathrm{~km}^{2}$ (latitude $24^{\circ} 28^{\prime}-25^{\circ} 28^{\prime}$ $\mathrm{N}$, longitude $102^{\circ} 30^{\prime}-103^{\circ} 00^{\prime} \mathrm{E}$ ) (Yang et al. 2009). Lake Dianchi was historically a clean water lake, serving as a major drinking water source for Kunming metropolitan area. However, the rapid urbanization and industrial development of Kunming that began in the 1980s has produced tremendous nutrient loads entering the lake, causing severe deterioration in lake water quality, among which Panlongjiang River and Daqinghe River poses the biggest loading flux and river flow into the lake. In the past two decades, Lake Dianchi has gradually lost its function as a major drinking water source and is now one of the three most heavily polluted lakes in China that the Chinese central government mandates to develop effective water quality management plans for and achieve significant water quality improvement (MEP 2008).

The Kunming Environmental Monitoring Center is responsible for monthly water quality monitoring. Data were collected from seven regular monitoring sites. The seven observation stations were Huiwanzhong (B6), Luojiaying (B5), Guanyinxi (B4), Guanyinzhong (B3), Guanyindong (B2), Baiyukou (B1), and Haikouxi (A2) (Fig. 1). Water samples were collected monthly and preserved, delivered, and analyzed using the standard methods 


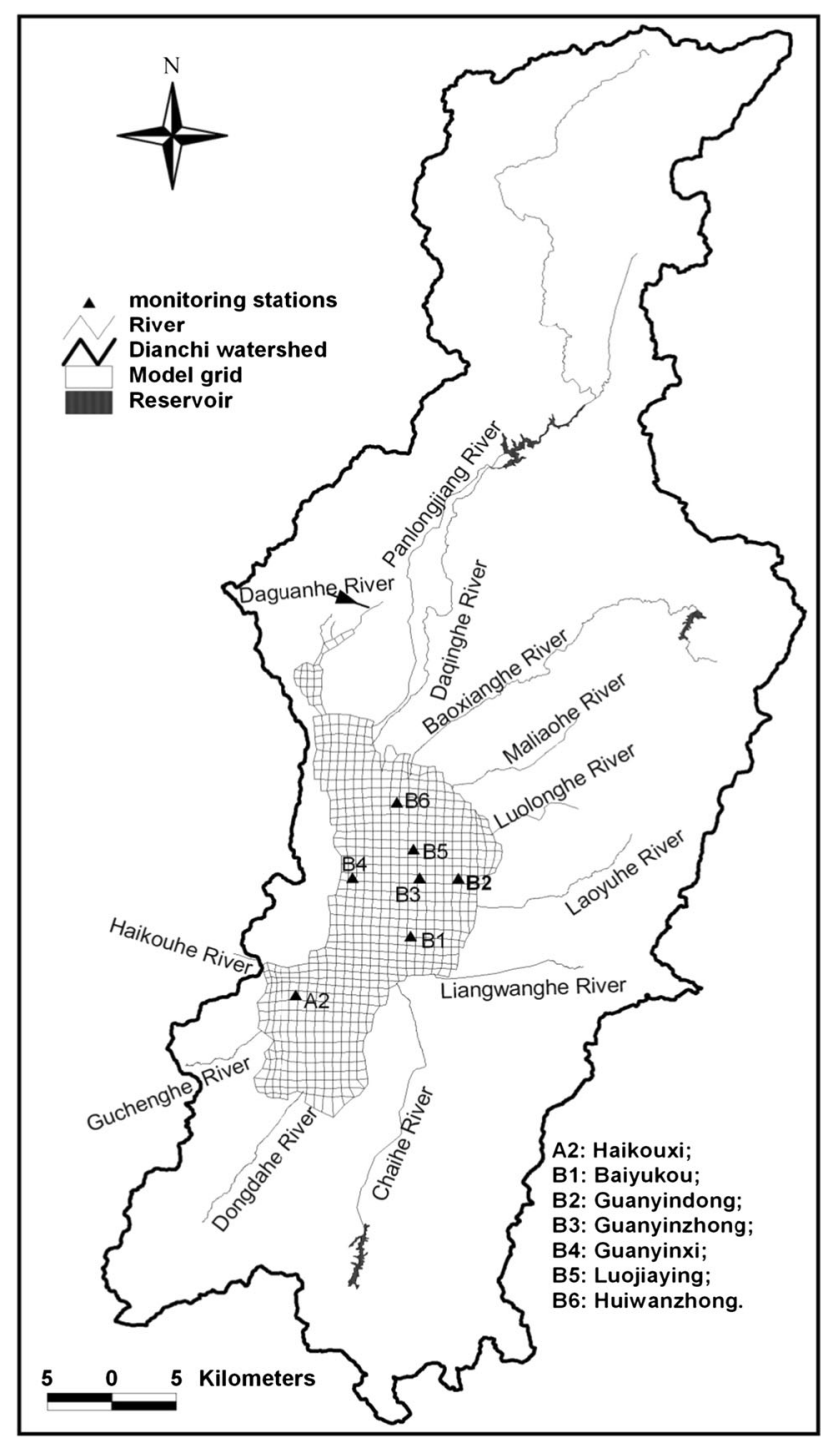

Fig. 1 Lake Dianchi watershed, model grid, and sampling stations

of the American Public Health Association (APHA 1998) and China's GB3838-2002 Standard. These data provided the basis for calibrating and validating the water quality model developed in this study.

\section{Theoretical framework}

Eutrophication in Lake Dianchi can be conceptualized as nutrient and algae dynamics primarily driven by external nutrient loading and internal recycling. In the water column, algae would uptake nutrients in the forms of ammonium, nitrate, and dissolved orthophosphate for growth. In the meantime, algae respiration, mortality and predation would release various forms of carbon, nitrogen and phosphorous back into the water (Sagehashi et al. 2000). The aerobic oxidation of organic carbon in the water column would exert a carbonaceous oxygen demand which can cause aquatic eco-system impairment due to low DO. In addition, the organic components of nitrogen and phosphorous from both watershed sources and algal metabolisms can also convert into inorganic forms through degradation processes.

The ultimate sources of nutrients are from watershed inflows and atmospheric deposition, which interact with algae and other components of aquatic ecological system after they enter the water column. A portion of particulate nutrients, however, can exit the water column by settling to the sediment bed. In the sediment bed, the deposited nutrients undertake diagenetic processes that in return generate sediment oxygen demand and upward flux of nitrogen and phosphorus. The upward nutrient flux would exert internal nutrient sources to the water column to provide significant fuel for algal bloom in shallow lakes. Apparently, the external nutrient sources from watershed and atmosphere, the fate and transport of the nutrient in the lake water column, and the sediment-water column interaction form three inexplicable components of the theoretical framework that are necessary for analyzing the effectiveness of load reductions schemes to restore Lake Dianchi.

\section{Computational platform}

The water quality model for Lake Dianchi was developed based on a sophisticated computational platform of Environmental Fluids Dynamics Code (EFDC). EFDC is a comprehensive one-, two-, or three-dimensional model capable of simulating hydrodynamics, salinity, temperature, eutrophication dynamics, and the fate and transport of toxic materials, using the FORTRAN language (Hamrick 1992, 1996; Park et al. 1995; Zou et al. 2008). The model uses sigma vertical coordinates and Cartesian or curvilinear, orthogonal horizontal coordinates to represent the physical characteristics of a water body, although a recent update now provides the capability for a General Vertical Coordinate (GVC) representation of water bodies with drastic bathymetry variation.

The hydrodynamic module of the model solves threedimensional, vertically hydrostatic, free surface and turbulent averaged equations of motion for a variable-density fluid. Dynamically coupled transport equations for turbulent kinetic energy, turbulent length scale, salinity, and temperature are also solved. For simplicity, the governing equations and numerical schemes of the EFDC hydrodynamic model will not be presented here, but are detailed in Hamrick (1992). The general governing equation of the water quality module of EFDC can be mathematically represented as 


$$
\begin{aligned}
& \frac{\partial\left(m_{x} m_{y} H C\right)}{\partial t}+\frac{\partial}{\partial x}\left(m_{y} H u C\right)+\frac{\partial}{\partial y}\left(m_{x} H v C\right)+\frac{\partial}{\partial z}\left(m_{x} m_{y} w C\right) \\
= & \frac{\partial}{\partial x}\left(\frac{m_{y} H A_{x}}{m_{x}} \frac{\partial C}{\partial x}\right)+\frac{\partial}{\partial y}\left(\frac{m_{x} H A_{y}}{m_{y}} \frac{\partial C}{\partial y}\right) \\
& +\frac{\partial}{\partial z}\left(m_{x} m_{y} \frac{A_{z}}{H} \frac{\partial C}{\partial z}\right)+m_{x} m_{y} H S_{c}
\end{aligned}
$$

where $C=$ concentration of a water quality state variable; $u, v, w=$ velocity components in the curvilinear, sigma x-, $\mathrm{y}-$, and z-directions, respectively; $A_{x}, A_{y}, A_{z}=$ turbulent diffusivities in the $\mathrm{x}-, \mathrm{y}-$, and $\mathrm{z}$-directions, respectively; $S_{c}=$ internal and external sources and sinks per unit volume; $H=$ water column depth; $m_{x}, m_{y}=$ horizontal curvilinear coordinate scale factors.

The last three terms on the left-hand side of Eq. (1) account for transport and the first three terms on the righthand side account for diffusive transport. These six terms for physical transport are solved using the same numerical method for temperature and salinity in the hydrodynamic model (Hamrick 1992). The last term in Eq. (1) represents the kinetic processes and external loads for each of the state variables. In EFDC, Eq. (1) is solved using a fractional step procedure that decouples the kinetic terms from the physical transport terms:

$$
\begin{aligned}
& \frac{\partial}{\partial t_{p}}\left(m_{x} m_{y} H C\right)+\frac{\partial}{\partial x}\left(m_{y} H u C\right)+\frac{\partial}{\partial y}\left(m_{x} H v C\right)+\frac{\partial}{\partial z}\left(m_{x} m_{y} w C\right) \\
& =\frac{\partial}{\partial x}\left(\frac{m_{y} H A_{x}}{m_{x}} \frac{\partial C}{\partial x}\right)+\frac{\partial}{\partial y}\left(\frac{m_{x} H A_{y}}{m_{y}} \frac{\partial C}{\partial y}\right) \\
& \quad+\frac{\partial}{\partial z}\left(m_{x} m_{y} \frac{A_{z}}{H} \frac{\partial C}{\partial z}\right)+m_{x} m_{y} H S_{\mathrm{CP}}
\end{aligned}
$$

$\frac{\partial C}{\partial t_{K}}=S_{\mathrm{CK}}$

leading to

$\frac{\partial}{\partial t}\left(m_{x} m_{y} H C\right)=\frac{\partial}{\partial t_{p}}\left(m_{x} m_{y} H C\right)+\left(m_{x} m_{y} H\right) \frac{\partial C}{\partial t_{K}}$
In Eqs. (2) and (3), the source-sink term in Eq. (1) has been split into physical sources and sinks $\left(S_{\mathrm{CP}}\right)$, which are associated in volumetric inflows and outflows, and kinetic sources and $\operatorname{sinks}\left(S_{\mathrm{CK}}\right)$.

The main steps for conducting EFDC include grid generation and preprocessing, input file preparation, code compiling and executing, diagnostic options and output, time series output and analysis, results output and visualization (Hamrick 1992). EFDC simulates 21 water column state variables as listed in Table 1 . The general interactions between these state variables are illustrated in Fig. 2. Water temperatures are needed for computation of the water quality state variables and they are provided by the internally coupled hydrodynamic model. More details about the model structure and equations can be found in Park et al. (1995).

In addition to representing the water column dynamics, a predictive water quality model must quantitatively represent the interactions between the water column and sediment in evaluating the response of water quality to external loadings for water bodies when internal nutrient loadings from sediments are significant. Lake Dianchi is a shallow lake with highly enriched sediment, whereby the internal nutrient loading from the benthic flux can be a significant contributor to the long-term eutrophication problem in the lake. Therefore, a critical component of the water quality model for Lake Dianchi is to have the capability of simulating the interactions between the sediment bed and water column water quality. The modeling framework for the sediment-water interaction simulation is the sediment diagenesis module in EFDC, which has 27 state variables representing the kinetic processes occurring in the sediment bed. The sediment module, upon receiving the particulate organic matter deposited from the overlying water column, simulates the diagenesis and the resulting fluxes of inorganic substances (ammonium, nitrate, phosphate, and silica) and sediment oxygen demand (SOD) back to the water column. The coupling of the sediment process model with the water column eutrophication model allows the water quality model to have a predictive
Table 1 EFDC model water quality state variables
(1) Algae group 1 (Bc)

(2) Algae group $2(\mathrm{Bd})$

(3) Algae group 2 (Bg)

(4) Refractory particulate organic carbon (RPOC)

(5) Labile particulate organic carbon (LPOC)

(6) Dissolved organic carbon (DOC)

(7) Refractory particulate organic phosphorus (RPOP)

(8) Labile particulate organic phosphorus (LPOP)

(9) Dissolved organic phosphorus (DOP)

(10) Total phosphate $\left(\mathrm{PO}_{4} \mathrm{t}\right)$

(11) Refractory particulate organic nitrogen (RPON)
(12) Labile particulate organic nitrogen (LPON)

(13) Dissolved organic nitrogen (DON)

(14) Ammonia nitrogen $\left(\mathrm{NH}_{4}\right)$

(15) Nitrate nitrogen $\left(\mathrm{NO}_{3}\right)$

(16) Particulate biogenic silica (SU)

(17) Dissolved available silica (SA)

(18) Chemical oxygen demand (COD)

(19) Dissolved oxygen (DO)

(20) Total active metal (TAM)

(21) Fecal coliform bacteria (FCB)

(22) Macrophyte/periphyton (Bm) 
Fig. 2 Schematic diagram of EFDC water quality model structure (Park et al. 1995)

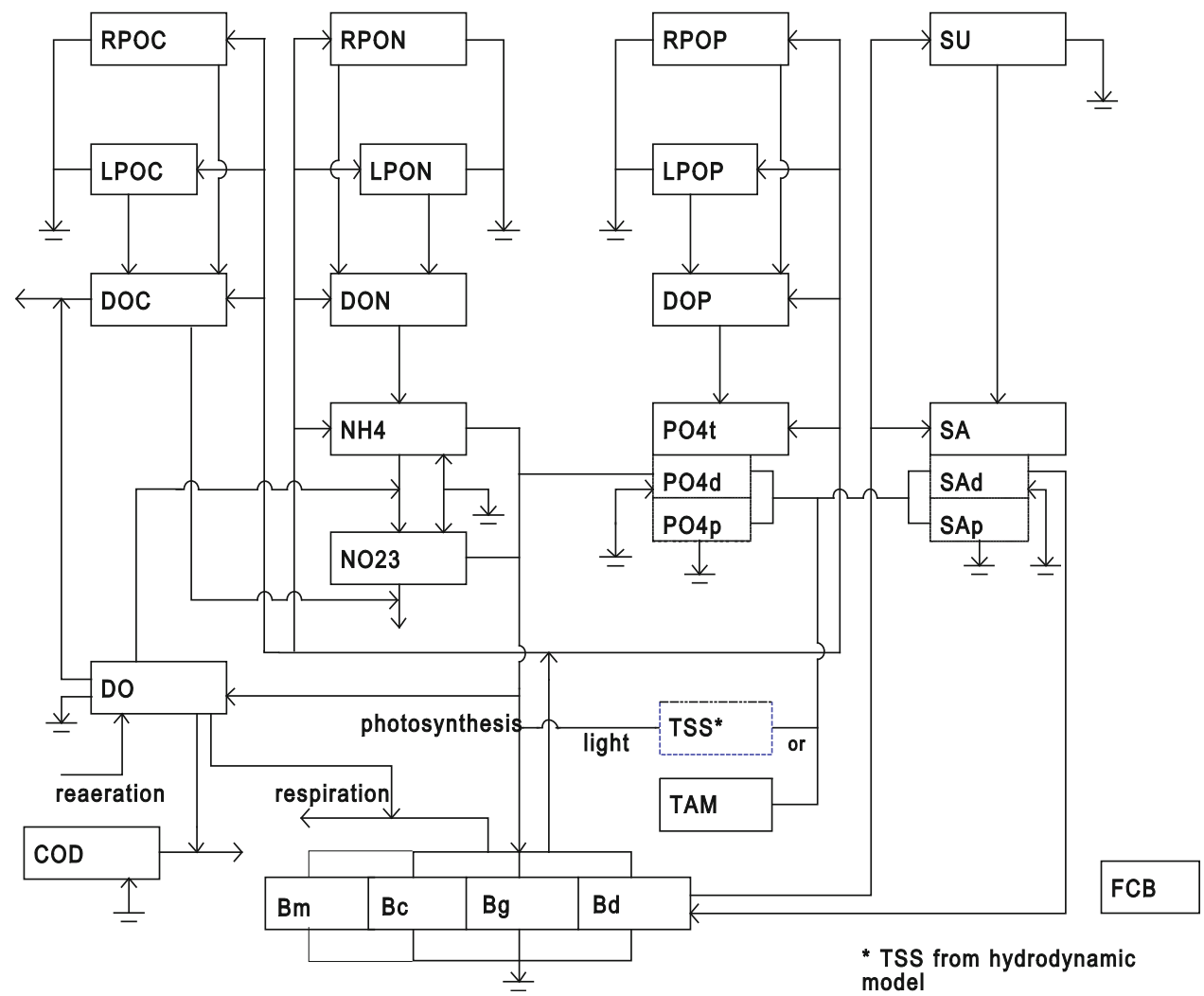

capability that enables long-term simulations of water quality following various load reduction conditions (Park et al. 1995).

\section{Model development}

Configuration of the EFDC hydrodynamic and water model for Lake Dianchi involved processing bathymetric data, developing a model grid, assigning initial hydrodynamic and water quality conditions in the water column, defining boundary conditions at the water surface, and linking to a watershed model for lateral flow and pollutant loading boundary conditions. The following discussion provides details regarding model configuration and application.

\section{Grid generation}

EFDC is a finite difference-based numerical modeling system; therefore, the first step to modeling Lake Dianchi with EFDC was to discrete the water body into a computational grid to solve the model's governing equations. A boundary-fit curvilinear grid was developed to most truly represent the shape of the lake. The grid consisted of 664 curvilinear grid cells. Each cell was represented using six layers to vertically resolve the light profile for accurate phytoplankton simulations, which resulted in 3,984 computational cells. Figure 1 presents the horizontal computational grid of the Lake Dianchi model.

\section{Kinetic complexity determination}

To accurately represent the complex chemical and biological interactions in the impaired water body, the highest kinetic complexity represented in the EFDC model was adopted. The water column state variables simulated in the water quality model included three groups of phytoplankton (Blue-green algae, diatom, green algae), DOC, LPOC, RPOC, DOP, LPOP, RPOP, $\mathrm{PO}_{4}, \mathrm{DON}, \mathrm{LPON}, \mathrm{RPON}$, $\mathrm{NH}_{4}, \mathrm{NO}_{2} / \mathrm{NO}_{3}$, dissolved oxygen (DO), and COD.

In addition to representing the chemical and biological interactions within the water column, a sediment diagenesis model was developed to couple the water column and sediment bed. It enables the prediction of benthic nutrient flux and SOD in response to external nutrient loading and water quality dynamics for not only historical conditions, but also for watershed management and restoration scenarios. This predictive capability overcomes the inherent limitation in many water quality models based on preset static water-sediment interactions. This is of critical importance for watershed management scenario analysis, 
whereby TMDL scenarios should (and in reality, would) have a direct impact on sediment nutrient contributions to the water column.

\section{Boundary conditions}

Model boundary conditions are external driving forces applied to the modeling system. The lateral boundary conditions include the tributary flow rate and associated temperature and pollutant loadings. The surface boundary condition is represented by time variable meteorological conditions including solar radiation, wind speed and direction, air temperature, atmospheric pressure, relative humidity, and cloud cover conditions.

In the Lake Dianchi model, lateral boundary conditions for flow and nutrients were configured based on the results of a previously developed watershed model for the Lake Dianchi watershed, which was based on the U.S. EPA's Generalized Watershed Loading Function (GWLF) modeling framework. The spatial representation of the lateral boundary conditions was determined by mapping the geographical coordinates of the tributary outlets to the model grid. Since the watershed model produced no result for DO, the corresponding boundary conditions for DO were configured based on observed data in the inflow tributaries. The temperature boundary condition was determined based on the simulated water temperature in the lake to reflect the general response of water temperature to atmospheric conditions. In addition to tributaries, atmospheric deposition is an additional nutrient source, the amount of which was estimated based on data to be approximately $0.04 \mathrm{mg} / \mathrm{L}$ of $\mathrm{PO}_{4}$ and $0.7 \mathrm{mg} / \mathrm{L}$ of $\mathrm{NO}_{3}$ in precipitation. This loading was represented in the EFDC model as a constant wet deposition term.

The EFDC model requires atmospheric boundary forcing data, which include atmospheric pressure, air temperature, relative humidity, precipitation, evaporation, solar radiation, cloud cover, wind speed, and wind direction to drive the hydrodynamic simulation. The wind data were obtained from three weather stations around Lake Dianchi, including Chenggong, Daguanlou, and Jinning stations, while other data were only from Daguanlou Station. The wind data were represented using the corresponding coordinates of the three weather stations, and the spatially variable wind field above Lake Dianchi was internally calculated in the EFDC model.

\section{Initial conditions}

Initial conditions provide an important starting point for the model. Since Lake Dianchi has a very long retention time, the impact of initial conditions can last for an extended period. For such a system, proper assignment of initial conditions serves as a critical step in developing the model. In this study, the year 2003 was selected as the simulation year based on data availability for model configuration and calibration; the available data at the beginning of the year was used to configure the initial conditions. Specifically, the observed surface elevation at the beginning of year 2003 was used to initialize the water depth across the entire lake. As for water quality, since significant spatial variability was demonstrated in the observed data, setting spatially variable initial conditions through interpolating the observed water quality concentration at seven locations in the lake was thus desirable.

The initial condition for the sediment bed posed a challenge for this modeling study due to a lack of data to characterize the general magnitude and spatial variability in the sediment bed. In light of this situation, an iterative approach was adopted to derive the initial bed condition through a calibration process. Specifically, the model was run using an assumed initial bed condition for 5 years with recycled boundary conditions, and then the resulting bed condition was used as the initial condition for the calibration run. This process was repeated until the final calibration was achieved.

\section{Results and discussion}

Before the model can be used to support water quality restoration decision making, its capability of representing the relationship between watershed loading and in-lake water quality should be established through a model calibration and validation processes. Model calibration involves adjusting parameter values within reasonable and acceptable ranges, so that the deviations between the model results and the measured data are minimized and are within some acceptable ranges of accuracy (Jin et al. 2007). Model validation is the subsequent testing of a calibrated model to a second independent data to further examine the model's ability to realistically represent the waterbody. In this study, there are two sets of independent data for the years 2003 and 2004, respectively. These data sets are used to calibrate and validate the Lake Dianchi water quality model.

The model was calibrated for the period from January 1 to December 31, 2003, through a comparison of model predictions with various observed data. The hydrodynamic model was calibrated with temperature and surface elevation data. The dynamic water quality model was then calibrated using the observed data of chlorophyll-a (Chl $a$ ), DO and multiple nutrient species.

The model calibration was conducted in a phased manner, whereby the hydrodynamic model was calibrated at first to make sure that the model reasonably represented 


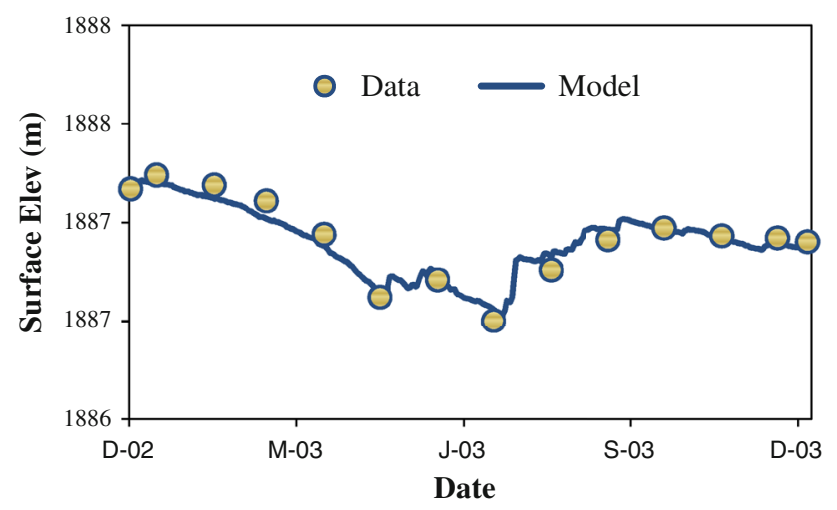

Fig. 3 Simulated versus observed water surface elevation

the flow and water temperature dynamics. The simulated water surface elevation was plotted against the data in Fig. 3, and the comparison between modeled and observed temperature at different monitoring stations are shown in Fig. 4. As shown, the model accurately mimicked the temporal variability in the water surface elevation and temperature throughout the year and across the lake. In general, both the model results and observed data show a decreasing trend in elevation from January to July; then the elevation rises from July to October before it levels off toward the end of the year, which reflects the intra-annual precipitation distribution whereby a majority of the rainfall occurs during the summer. In addition to the water balance, the temporal and spatial water temperature pattern in the lake were also well reproduced by the model, providing a physical basis for further calibrating the water quality model since all the kinetic process of water quality constituents are dependent on temperature.

The water quality model calibration was conducted to enable the model reproduce the observed water quality patterns in the lake. The simulated water quality was compared with observed data and key kinetic parameters were adjusted until a reasonable match between model results and data was achieved. The key parameters adjusted during the calibration process included nutrient- and algalrelated parameters. Table 2 shows the calibrated values of the key parameters.

Figure 4 plots simulated surface $\mathrm{NH}_{4}, \mathrm{DO}$, total nitrogen (TN), and total phosphorus (TP) concentrations against observed data at six monitoring stations in Lake Dianchi. The observed data demonstrate significant temporal variability in water quality due to the dynamic features in watershed loadings and in-lake processes, and the figure shows that the model reproduced both the spatial and temporal patterns of the observed data, indicating a good representation of the lake. Considering the sparseness in water quality data availability, it is not desired to calculate error statistics to measure the model performance because error statistics based on limited data can be misleading and has no statistically significant meaning (Zou and Lung 2004).

As shown in Fig. 4, both the model results and observed data show that $\mathrm{NH}_{4}$ concentration dropped sharply during the first two months, which was likely caused by the lack of sufficient inflow loadings during this dry season while the early spring algal bloom in the lake uptakes significant amount of $\mathrm{NH}_{4}$ to fuel the growth. Accompanying the sharp drop in $\mathrm{NH}_{4}$, we observed in both the model results and measured data that DO tended to increase from January to February to reach a super-saturated condition, which also suggests a spring algal bloom. The simulated chlorophyll-a match the observed data well and shows an increasing trend during the first two months of the year that corresponding to the early bloom. The chlorophyll-a then decreases from February to March, indicating a collapse of the early spring bloom likely due to the limitation from depleted nutrient concentration.

Another interesting observation is that the DO concentration in the water column correlates with the chlorophylla trend very well, where increasing in chlorophyll-a always accompanies increase in DO concentration. It appears that majority of the fluctuation in DO concentration is associated with chlorophyll-a variability, indicating a good match between modeled and observed DO can be an evidence of good calibration of algae. This is particularly meaningful in this modeling study because chlorophyll-a data were available for only three times a year, while much more DO data were available. Therefore, even though the good match between simulated and observed chlorophyll-a might not be sufficient to prove a good calibration of algal dynamics, the well calibrated DO trend does provide additional evidence that the algae dynamics were well represented. In addition, it should be mentioned that DO and chlorophyll-a are related in that when primary production is strong, it would induce super-saturation of DO; however, DO concentration and chlorophyll-a concentration cannot be directly correlated because DO is the result of almost all water quality processes. A good representation of the algal dynamics is important for developing the decision support tool for Lake Dianchi since majority of the restoration efforts are dedicated to control algal bloom in the lake.

To further establish the credibility of the Lake Dianchi model, the independent data in 2004 were used to validate the model. The validation involves applying the calibrated model to the year 2004 without changing any parameter values, and the simulated water quality conditions were compared against the observed values to evaluate the capability of the model to represent the real system. Figure 5 plots the model simulated water quality against observed value. As shown, the model again mimics the 


$$
\begin{array}{llll}
\text { Temp } & - & \text { DO } & \text { Temp Data } \\
\Delta \text { DO Data } & \text { Chla } & \text { O Chla Data }
\end{array}
$$
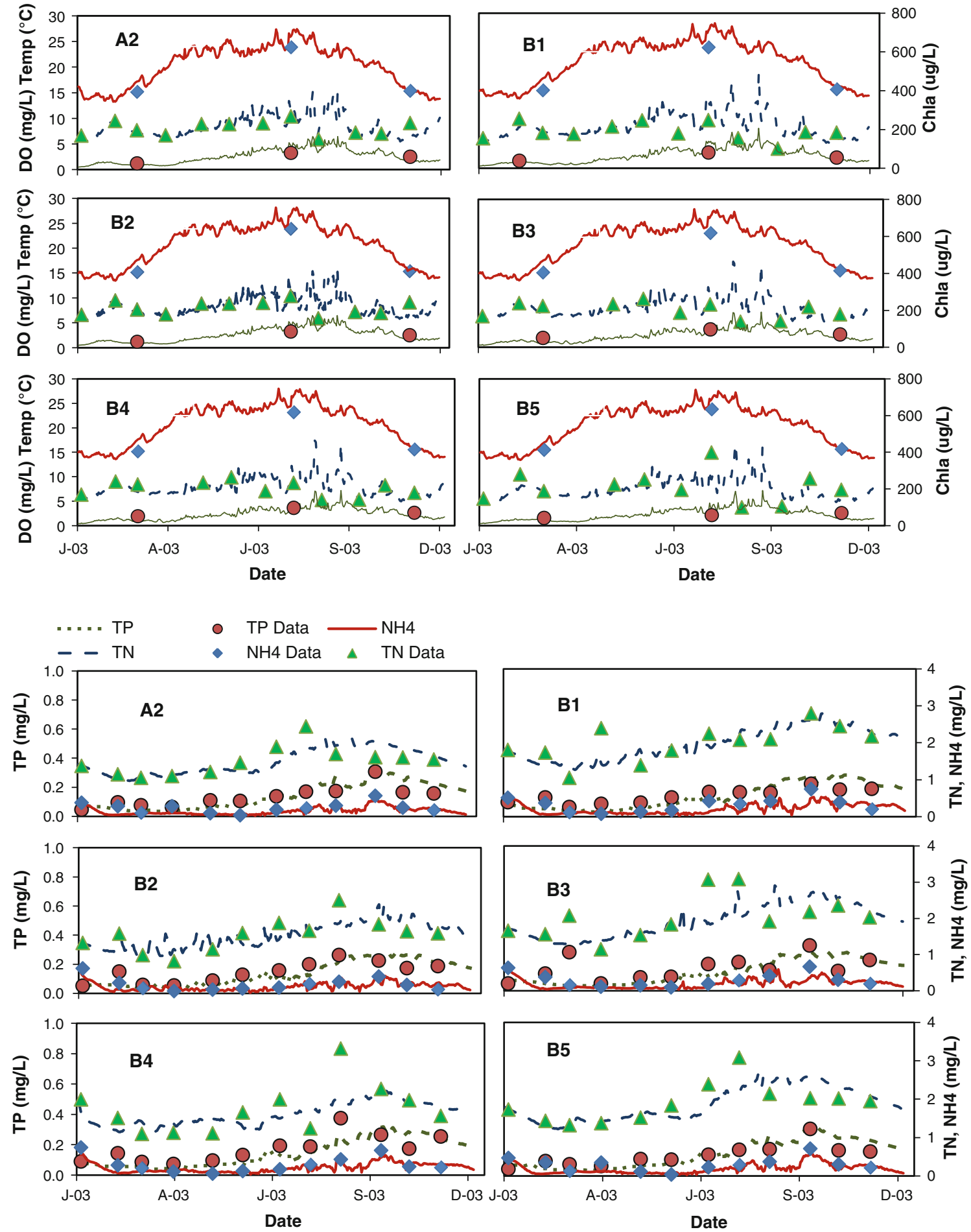

Fig. 4 Model calibration: simulated water quality versus observed data at six monitoring stations 
Table 2 Calibrated values for the key water quality parameters

\begin{tabular}{|c|c|c|c|}
\hline Parameter & Description & Value & References \\
\hline $\mathrm{P}_{\mathrm{a}}$ & $\begin{array}{l}\text { Max growth rate of algae } \\
\text { group } 1\end{array}$ & 2.95/day & $0.2-9.0$ \\
\hline $\mathrm{P}_{\mathrm{b}}$ & $\begin{array}{l}\text { Max growth rate of algae } \\
\text { group } 2\end{array}$ & 2.8/day & $0.2-9.0$ \\
\hline $\mathrm{P}_{\mathrm{c}}$ & $\begin{array}{l}\text { Max growth rate of algae } \\
\text { group } 3\end{array}$ & 2.5/day & $0.2-9.0$ \\
\hline $\mathrm{R}_{\mathrm{a}}$ & $\begin{array}{l}\text { Basal respiration rate of } \\
\text { algae group } 1\end{array}$ & $0.14 /$ day & $0.01-0.92$ \\
\hline $\mathrm{R}_{\mathrm{b}}$ & $\begin{array}{l}\text { Basal respiration rate of } \\
\text { algae group } 2\end{array}$ & $0.15 /$ day & $0.01-0.92$ \\
\hline $\mathrm{R}_{\mathrm{c}}$ & $\begin{array}{l}\text { Basal respiration rate of } \\
\text { algae group } 3\end{array}$ & $0.14 /$ day & $0.01-0.92$ \\
\hline $\mathrm{D}_{\mathrm{a}}$ & $\begin{array}{l}\text { Predation death rate of } \\
\text { algae group } 1\end{array}$ & 0.04/day & $0.03-0.3$ \\
\hline $\mathrm{D}_{\mathrm{b}}$ & $\begin{array}{l}\text { Predation death rate of } \\
\text { algae group } 2\end{array}$ & $0.15 /$ day & $0.03-0.3$ \\
\hline $\mathrm{D}_{\mathrm{c}}$ & $\begin{array}{l}\text { Predation death rate of } \\
\text { algae group } 3\end{array}$ & 0.04/day & $0.03-0.3$ \\
\hline $\mathrm{KEb}$ & $\begin{array}{l}\text { Background light } \\
\text { extinction coefficient }\end{array}$ & $0.3 / \mathrm{m}$ & $0.25-0.45$ \\
\hline $\mathrm{KEc}$ & $\begin{array}{l}\text { Chlorophyll-a induced } \\
\text { light extinction } \\
\text { coefficient }\end{array}$ & $\begin{array}{l}0.012 \text { per } \\
\text { ug/L }\end{array}$ & $0.002-0.02$ \\
\hline $\mathrm{KHN}_{\mathrm{a}}$ & $\begin{array}{l}\text { Nitrogen half saturation } \\
\text { coefficient for algae } \\
\text { group } 1\end{array}$ & $0.02 \mathrm{mg} / \mathrm{L}$ & $0.006-4.32$ \\
\hline $\mathrm{KHN}_{\mathrm{b}}$ & $\begin{array}{l}\text { Nitrogen half saturation } \\
\text { coefficient for algae } \\
\text { group } 2\end{array}$ & $0.02 \mathrm{mg} / \mathrm{L}$ & $0.006-4.32$ \\
\hline $\mathrm{KHN}_{\mathrm{c}}$ & $\begin{array}{l}\text { Nitrogen half saturation } \\
\text { coefficient for algae } \\
\text { group } 3\end{array}$ & $0.02 \mathrm{mg} / \mathrm{L}$ & $0.006-4.32$ \\
\hline $\mathrm{KHP}_{\mathrm{a}}$ & $\begin{array}{l}\text { Phosphorus half } \\
\text { saturation coefficient } \\
\text { for algae group } 1\end{array}$ & $0.001 \mathrm{mg} / \mathrm{L}$ & $0.001-1.52$ \\
\hline $\mathrm{KHP}_{\mathrm{b}}$ & $\begin{array}{l}\text { Phosphorus half } \\
\text { saturation coefficient } \\
\text { for algae group } 2\end{array}$ & $0.001 \mathrm{mg} / \mathrm{L}$ & $0.001-1.52$ \\
\hline $\mathrm{KHP}_{\mathrm{c}}$ & $\begin{array}{l}\text { Phosphorus half } \\
\text { saturation coefficient } \\
\text { for algae group } 3\end{array}$ & $0.001 \mathrm{mg} / \mathrm{L}$ & $0.001-1.52$ \\
\hline $\mathrm{TMR}_{\mathrm{a}}$ & $\begin{array}{l}\text { Optimal temperature } \\
\text { range for algae group } 1\end{array}$ & $26-30{ }^{\circ} \mathrm{C}$ & N/A \\
\hline $\mathrm{TMR}_{\mathrm{b}}$ & $\begin{array}{l}\text { Optimal temperature } \\
\text { range for algae group } 2\end{array}$ & $10-15^{\circ} \mathrm{C}$ & N/A \\
\hline $\mathrm{TMR}_{\mathrm{c}}$ & $\begin{array}{l}\text { Optimal temperature } \\
\text { range for algae group } 3\end{array}$ & $22-25{ }^{\circ} \mathrm{C}$ & N/A \\
\hline $\mathrm{S}_{\mathrm{a}}$ & $\begin{array}{l}\text { Settling rate of algae } \\
\text { group } 1\end{array}$ & $0.10 \mathrm{~m} /$ day & $0.001-13.20$ \\
\hline $\mathrm{S}_{\mathrm{b}}$ & $\begin{array}{l}\text { Settling rate of algae } \\
\text { group } 2\end{array}$ & $0.25 \mathrm{~m} /$ day & $0.001-13.20$ \\
\hline $\mathrm{S}_{\mathrm{c}}$ & $\begin{array}{l}\text { Settling rate of algae } \\
\text { group } 3\end{array}$ & $0.15 \mathrm{~m} /$ day & $0.001-13.20$ \\
\hline SRP & $\begin{array}{l}\text { Settling rate of refractory } \\
\text { organic matters }\end{array}$ & $0.2 \mathrm{~m} /$ day & $0.02-9.0$ \\
\hline
\end{tabular}

Table 2 continued

\begin{tabular}{llll}
\hline Parameter & Description & Value & References \\
\hline SLP & $\begin{array}{c}\text { Settling rate of labile } \\
\text { organic matters }\end{array}$ & $0.2 \mathrm{~m} /$ day & $0.02-9.0$ \\
KRN & RPON hydrolysis rate & $0.001 /$ day & 0.001 \\
KLN & LPON hydrolysis rate & $0.04 /$ day & $0.01-0.63$ \\
KDN & DON decay rate & $0.05 /$ day & $0.01-0.63$ \\
KRP & RPOP hydrolysis rate & $0.001 /$ day & 0.001 \\
KLP & LPOP hydrolysis rate & $0.04 /$ day & $0.01-0.63$ \\
KDP & DOP decay rate & $0.05 /$ day & $0.01-0.63$ \\
KRC & RPOC hydrolysis rate & $0.001 /$ day & 0.001 \\
KLC & LPOC hydrolysis rate & $0.05 /$ day & $0.01-0.63$ \\
KDC & DOC decay rate & $0.07 /$ day & $0.01-0.63$ \\
KN & Base nitrification rate & $0.05 /$ day & $0.001-1.3$ \\
\hline
\end{tabular}

observed water quality well, suggesting that the model parameterization derived through the calibration process is robust for representing a distinct year, providing additional evidence that the model has represented the reality well.

Both the calibration and validation simulation demonstrate that during the summer period, the DO concentration rose to a very high concentration well above the saturation level, which was caused by the intensive summer algal bloom in the lake. The drastic increase in DO level during summer occurs has been well documented for the hypereutrophic lakes where algal bloom causes super-saturation condition. Comparing the magnitude of summer DO at the north lake station of Huiwanzhong and that at the south lake station of Haikouxi, the peak DO value in the north lake was clearly significantly higher than that in the south lake, suggesting a more intensive algal bloom in the north lake. This pattern agrees with the general observations in Lake Dianchi (Yang et al. 2009), which can be explained by the high nutrient input loading to the north side of the lake from the main tributaries, the Daqinghe and Panlongjiang rivers; this will be discussed further under scenario analysis.

During the dry period, the loading signal from the tributaries is significant only at the north lake station of Huiwanzhong. However, during the wet period, we observed spikes of increased nutrient concentration at all stations. Note that after watershed loadings caused a spike in $\mathrm{NH}_{4}$ concentration, the spike turned into a sharp downtrend until an external loading event produced another spike. The downturn of $\mathrm{NH}_{4}$ following a spike was likely caused by a combined effect from dilution due to mixing along with stimulated algae activities caused by increased nutrient concentration, which quickly took up inorganic nutrient and depleted the concentration in the water column. 

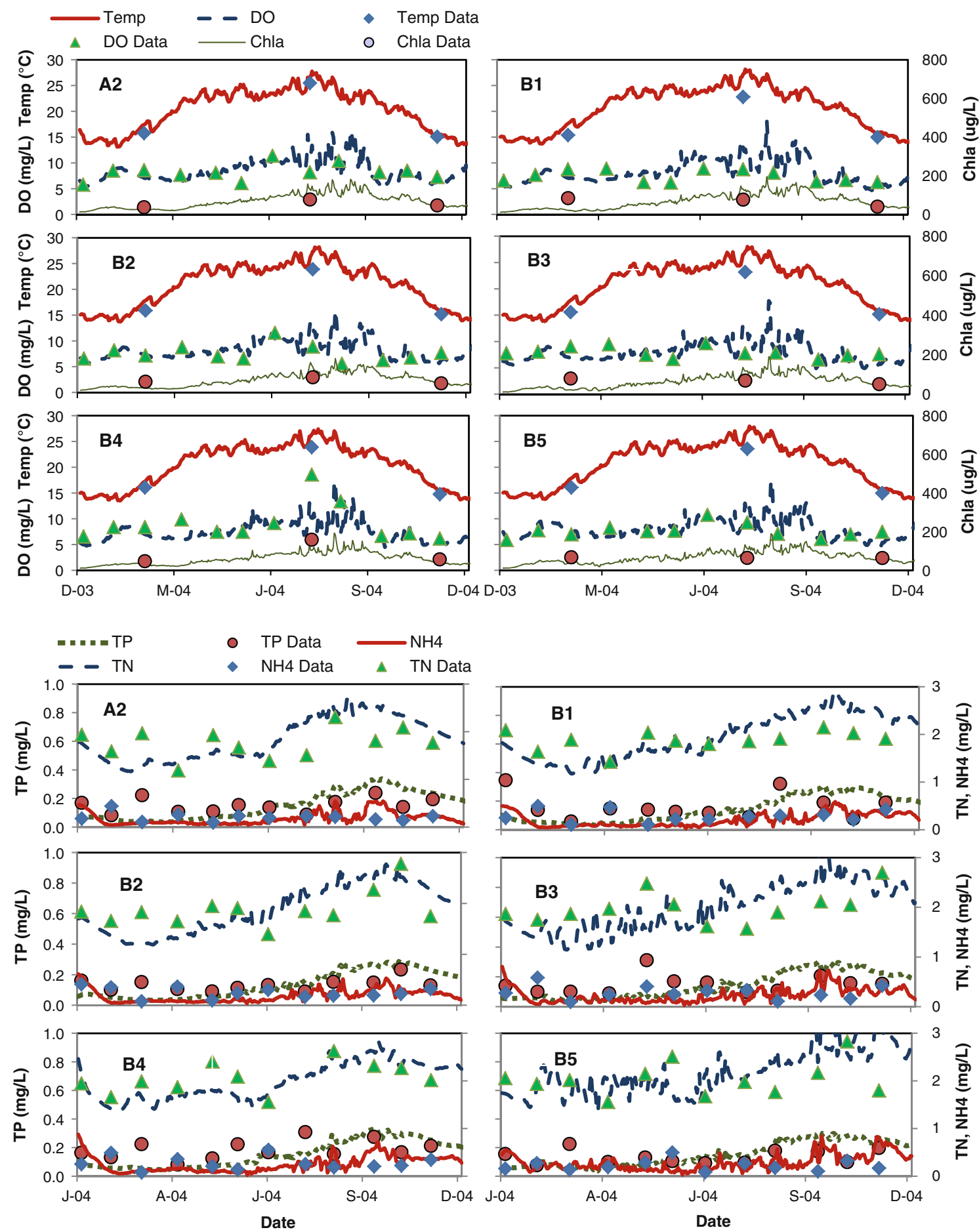

Fig. 5 Model validation: simulated water quality versus observed data for 2004

In summary, the model in general captures the spatial and temporal distribution of water quality well, although a few minor disparities exist between the model result and data at certain locations and times, which can be attributed to the uncertainty in both the model and data. However, these disparities between model and data are acceptable for the decision support purpose as the model has been shown to represent the overall dynamics well in the calibration and validation simulations. 
TMDL and restoration scenario analysis

Three TMDL scenarios were conducted to derive the load reduction requirement for achieving a series of water quality targets. The water quality targets for Lake Dianchi were set based on the China Environmental Quality Standards for Surface Water (EQSSW) system, which specifies different concentration targets based on different water quality classifications. For Lake Dianchi, the proposal was made to reach the Class V target of EQSSW as an initial objective of pollution control and then explore the feasibility of reaching Classes IV and III.

In this study, iterative model scenario runs were conducted to find that to reach the Classes III, IV, and V water quality targets, an 80,66 , and $54 \%$ reduction, respectively, would be required in nutrient loading from the watershed. Apparently, none of these reduction rate requirements are an easy goal to be accomplished. As shown, even to meet the lowest level goal would require an approximately $50 \%$ reduction in the existing loading level, which can take a long time and tremendous effort to achieve. Therefore, in the present and near future, governmental and other related parties should base their water quality goals on the Class $\mathrm{V}$ target and implement management schemes accordingly.

Quantitative analysis: water quality responses under TMDL scenarios

The preliminary TMDL result provides a basic framework for decision making; however, a refined and quantitative analysis will be more powerful to evaluate various key water quality restoration schemes. Therefore, the model was applied to conduct a series of scenario analysis through simulating how the in-lake algal bloom intensity responds to various load reduction schemes. To execute such an analysis, a baseline scenario was formulated based on the existing loading level as in the calibration model, but with recycling the boundary conditions for the last 40 years to simulate the long-term trend; the results of the 40 year were used as the basis of comparison. The major reason for the long-term simulation was to explicitly represent the response of internal nutrient sources from the sediment to changes in external loadings under different scenarios. Through preliminary scenario runs it was found that approximately 40 years of continuous simulation was required to allow reach quasi-steady state, therefore, all the scenarios were run to 40 years to provide consistent and stabilized results for comparison.
Two experimental scenarios proposed by the local decision makers, with the three TMDL scenarios, were configured based on the baseline model, but reducing the nutrient loadings at various levels and from different sources. They were proposed by decision makers to help understand why the past restoration produced no response in the lake. The two scenarios are:

1. All but P and D: remove $100 \%$ of nutrient loadings from all tributaries except for Panlongjiang River (P) and Daqinghe River (D);

2. $\mathrm{P}$ and D only: remove $100 \%$ of nutrient loadings from Panlongjiang and Daqinghe rivers, but keep the loadings from all other tributaries at the baseline level.

All five scenarios were run for 40 years in the same manner as the baseline analysis and the resulting time variable, chlorophyll-a concentration, for the 40 year was compared against the baseline result in Fig. 6. In later text, the Panlongjiang and Daqinghe rivers will be referred to as the Group 1 tributaries and all other tributaries as Group 2 tributaries.

Note in panel A of Fig. 6, the simulated chlorophyll-a concentration for Scenario 1 is very close to the baseline result, indicating that even with a unrealistic $100 \%$ nutrient reduction from all of the Group 2 tributaries, the algal bloom intensity in the lake would still likely be the same as the pre-control condition. Actually, this scenario represents an extreme condition whereby the $100 \%$ of nutrient loadings are removed from those tributaries. In reality, the reduction level would be much lower than the extreme $100 \%$; therefore, it can be inferred that managing the Group 2 tributaries alone would be unlikely to produce any visible improvement in algal bloom control. This result helps the decision- makers understand why the past watershed pollution control measures which focused on non-point source controls associated with these tributaries produced no detectable response in algal bloom intensity.

In contrast, Scenario 2 results show that the algal bloom in Lake Dianchi respond to control of loadings from Panlongjiang and Daqinghe Rivers significantly. With all the Group 2 tributaries un-controlled, removing the loadings from Panlongjiang and Daqinghe Rivers would significantly depress the algal bloom in the lake. This scenario helps the decision-makers identify the key for directing future resources in control algal blooms in the lake. It should be noted that Scenarios 1 and 2 are only experimental analysis, which were not designed to 

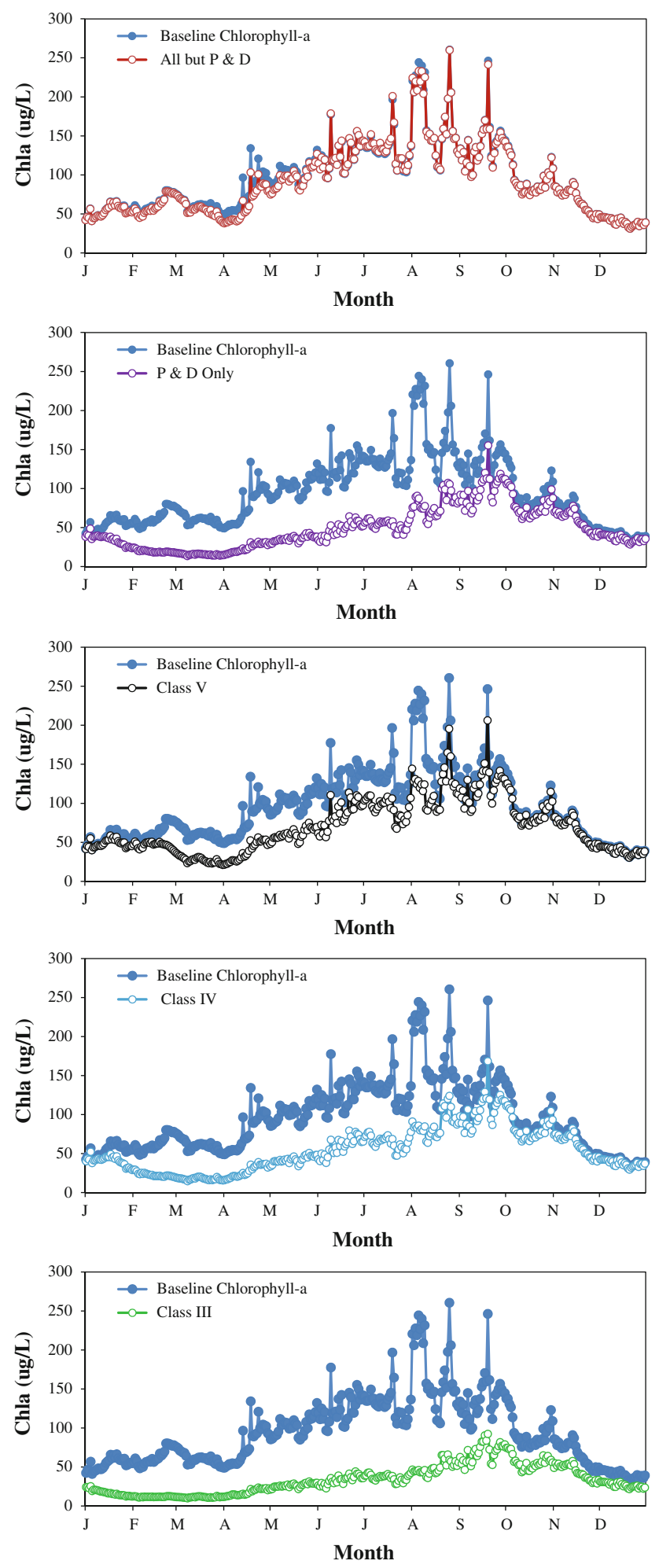

Fig. 6 Comparing simulated chlorophyll-a concentration between baseline and load reduction scenarios

directly guide future decision making since it is not realistic to control a group of tributaries to extremely high level while leaving other tributaries alone.
The three TMDL scenarios were designed to provide more realistic guidance for decision making. The results of the TMDL scenarios were plotted against the baseline results in panel $\mathrm{C}$ to $\mathrm{E}$ of Fig. 6. As shown, with the increasing load reduction ratio, the algal bloom in Lake Dianchi is significantly depressed due to insufficient inlake nutrient levels to sustain the fast growth of phytoplankton. However, the results of scenario 5 also show that even the water quality reaches Class III, which is very high for Lake Dianchi to compliance, the peak chlorophyll-a can still reach a level $>50 \mu \mathrm{g} / \mathrm{L}$. There is a relatively high risk of algal bloom. The scenario results presented above demonstrate the difficulty of achieving a significant depression in algal bloom intensity in Lake Dianchi.

As shown above, the model developed in this study reproduced the observed data well, providing the first quantitative decision support tool for the lake Dianchi water quality restoration. The current model can be applied to evaluate more sophisticated load reduction and allocation scenarios for guiding current pollution control programs. In the meantime, it will be expected to further update the current model using recently collected data, and continue to provide refined decision support for future lake restoration efforts.

\section{Conclusion}

A three-dimensional and hydrodynamic water quality model was developed to simulate the fate and transport of nutrients, along with the eutrophication dynamics in Lake Dianchi, China. The model explicitly simulates the physical, chemical, and biological processes that are very important in understanding the eutrophication dynamics in the lake. This modeling study led to the following observations and conclusions.

1. Overall, the model reproduced the observed temporal and spatial water quality patterns in the lake represented by two independent data sets, suggesting that the model represent the eutrophication dynamics in the lake well.

2. The model was applied to conduct a series of TMDL scenario analyses and the results indicate that achieving observable algal control in the lake would be very difficult. A significant depression of chlorophyll-a concentration in the lake would require drastic nutrient load reductions from the inflowing tributaries.

3. Internal nutrient sources from the sediment would provide a long-lasting influx of nutrient to the water column to sustain phytoplankton growth, causing extensive simulation periods to be used, i.e., 40 years 
to produce quasi-steady state results for scenario evaluation.

4. The modeling study found that significant watershed pollutant reduction would be required even to achieve the lowest level of water quality targets (Class V), suggesting that a phased approach should be adopted to set a site-specific water quality target. Complete compliance at the highest target level (Class III) would require approximately $80 \%$ loading reduction, which seems infeasible based on available management technologies.

5. Future research should focus on refining the model with more intensive and accurate data and conserving the role of air deposition, hence allowing the model to evolve along the process of watershed management and pollutant control to provide real-time environmental management decision support.

Acknowledgments This paper was supported by the "China National Water Pollution Control Program" (2013ZX07102-006) and National Natural Science Foundation of China (Grant No. 41222002 and U0833603).

\section{References}

Ahmad S, Khan IH, Parida BP (2001) Performance of stochastic approaches for forecasting river water quality. Water Res 35(18):4261-4266

American Public Health Association (APHA) (1998) Standard methods for the examination of water and wastewater. American Public Health Association, Washington

Chapra SC (1997) Surface Water Quality Modeling. The McGRAWHILL Company, INC., New York

Conley DJ, Paerl HW, Howarth RW, Boesch DF, Seitzinger SP, Havens KE, Lancelot C, Likens GE (2009) Controlling eutrophication: nitrogen and phosphorus. Science 323:1014-1015

Diaz RJ, Rosenberg R (2008) Spreading dead zones and consequences for marine ecosystems. Science 321:926-929

Gurkan Z, Zhang J, Jørgensen SE (2006) Development of a structurally dynamic model for forecasting the effects of restoration of lakes. Ecol Model 197:89-103

Hamrick JM (1992) A three-dimensional environmental fluid dynamics computer code: theorectical and computational aspects. Special paper 317, the College of William and Mary, Virginia Institute of Marine Science, Williamsburg

Hamrick John M (1996) User's Manual for the Environmental Fluid Dynamics Computer Code. Special Report No. 331 in Applied Marine Science and Ocean Engineering. Department of Physical Sciences, School of Marine Science, Virginia Institute of Marine Science, The College of William and Mary, Gloucester Point

Jin KR, Ji ZG, James RT (2007) Three dimensional water quality and SAV modeling of a large shallow lake. J Great Lakes Res $33: 28-45$
Liu Y, Guo HC, Wang LJ, Dai YL, Zhang XM, Li ZH, He B (2006) Dynamic phosphorus budget for lake-watershed ecosystems. J Environ Sci 18(3):596-603

Liu Y, Guo HC, Yu YJ, Dai YL, Zhou F (2008a) Ecologicaleconomic modeling as a tool for lake-watershed management: a case study of Lake Qionghai Watershed, China, pp 89-104

Liu Y, Yang PJ, Hu C, Guo HC (2008b) Water quality modeling for load reduction under uncertainty: a Bayesian approach. Water Res 42(13):3305-3314

Lung WS (2001) Water Quality Modeling for Wasteload Allocations and TMDL. Wiley Inc., NY

Martins G, Ribeiro DC, Pacheco D, Cruz JV, Cunha R, Goncalves V, Nogueira R, Brito AG (2008) Prospective scenarios for water quality and ecological status in Lake Sete Cidades (Portugal): the integration of mathematical modelling in decision processes. Appl Geochem 23(8):2171-2181

Ministry of Environmental Protection of China (MEP) (2008) Report on the State of the Environment in China 2007. http:// english.mep.gov.cn/standards_reports/soe/soe2007/200909/t200 90902_159820.htm Accessed on Jan 242010

National Research Council (2001) Assessing the TMDL Approach to Water Quality Management. National Academy Press, Washington

Park K, Kuo A, Shen J, Hamrick J (1995) (rev. by Tetra Tech, Inc. 2000). A Three-dimensional Hydrodynamic-Eutrophication Model (HEM-3D): Description of Water Quality and Sediment Process Submodels (EFDC Water Quality Model). Special Report No. 327 in Applied Marine Science and Ocean Engineering

Pelley J (2003) New watershed approach rooted in TMDL. Environ Sci Technol 37(21):388A

Sagehashi M, Sakoda A, Suzuki M (2000) A predictive model of long-term stability after biomanipulation of shallow lakes. Water Res 34:4014-4028

Smith VH, Tilman GD, Nekola JC (1999) Eutrophication: impacts of excess nutrient inputs of freshwater, marine, and terrestrial ecosystems. Environ Pollut 100:179-196

Vieira JMP, Lijklema L (1989) Development and application of a model for regional water quality management. Water Res 23:767-777

World Bank (2001) China: Air, Land, and Water. Washington, D.C., USA. http://www.worldbank.org.cn/English/content/chinaenvironment.pdf

Yang YH, Zhou F, Guo HC, Sheng H, Liu H, Dao X, He CJ (2009) Analysis of spatial and temporal water pollution patterns in Lake Dianchi using multivariate statistical methods. Environ Monit Assess doi:10.1007/s10661-009-1242-9

Zhao X, Shen Z, Xiong M, Qi J (2011) Key uncertainty sources analysis of water quality model using the first order error method. Int J Environ Sci Tech 8(1):137-148

Zheng Y, Keller AA (2008) Stochastic watershed water quality simulation for TMDL development - a case study in the newport bay watershed. J Am Water Resour Assoc 44(6):13971410

Zou R, Lung WS (2004) Robust water quality modeling using alternating fitness genetic algorithm. J Water Resour Plann Manag 130(6):471-479

Zou R, Carter S, Shoemaker L, Parker A, Henry T (2006) An Integrated hydrodynamic and water quality modeling system to support nutrient TMDL development for Wissahickon Creek. J Environ Eng ASCE 132(4):555-566 
Zou R, Bai S, Parker A (2008) Hydrodynamic and eutrophication modeling for a tidal marsh impacted estuarine system using EFDC. Coast Estuary Model 11:561-589
Zou R, Lung WS, Wu J (2009) Multiple-pattern parameter identification and uncertainty analysis approach for water quality modeling. Ecol Model 220:621-629 